Research Article

\title{
Improved Sound Absorption Properties in Polyurethane Foams by the Inclusion of $\mathrm{Al}_{2} \mathrm{O}_{3}$ Nanoparticles
}

\author{
Binxia Yuan $\mathbb{D}^{1,2}$ Xinyi Fang, ${ }^{2}$ Jianben Liu, ${ }^{1}$ Yan Liu, ${ }^{1}$ and Rui $\mathrm{Zhu}^{2}$ \\ ${ }^{1}$ State Key Laboratory of Power Grid Environmental Protection, Wuhan 430070, China \\ ${ }^{2}$ Shanghai University of Electric Power, Shanghai 200090, China \\ Correspondence should be addressed to Binxia Yuan; yuanbinxia100@163.com
}

Received 28 May 2021; Revised 10 September 2021; Accepted 22 September 2021; Published 30 September 2021

Academic Editor: Abdullah Seçgin

Copyright (c) 2021 Binxia Yuan et al. This is an open access article distributed under the Creative Commons Attribution License, which permits unrestricted use, distribution, and reproduction in any medium, provided the original work is properly cited.

At present, the scale of China's power grid is becoming larger and larger, and the control of low-frequency noise in substations (especially for transformers) is very important. The sound-absorbing materials have become one of the important ways to control low-frequency noise. The single polyurethane material cannot satisfy the requirements for reducing low-frequency noise, so it is very necessary to study its composite with other materials. In the paper, the flexible polyurethane foam and $\mathrm{Al}_{2} \mathrm{O}_{3}$ nanoparticle composites were obtained by the impregnation method. The method was simple, safe, and easy to control. The morphology and sound absorption coefficient of the foam materials before and after filling were analyzed. Single-hole acoustic cavity models of PU and $\mathrm{Al}_{2} \mathrm{O}_{3}-\mathrm{PU}$ composite were established through the finite element. The absorption and dissipation process of sound pressure for single hole was studied to understand the energy dissipation process. Meanwhile, through studying acoustic energy storage and acoustic energy dissipation, the loss factor of a single hole was obtained, which can predict the change rule of the sound absorption coefficient for $\mathrm{PU}$ foam and $\mathrm{Al}_{2} \mathrm{O}_{3}$-PU.

\section{Introduction}

With the development of national economic and social progress, the accompanying environmental issues have attracted more and more attention from the country and the people. At present, four pollution problems are concerned, such as water pollution, air pollution, solid waste, and noise pollution. Among them, noise pollution has an increasing impact on people's lives [1]. How to control noise pollution and reduce the harm of noise to the human body is concerned by scientific researchers [2]. The treatment of lowfrequency noise in substations has received lots of attention, and using sound-absorbing materials to reduce noise has become one of the important ways to control low-frequency noise [3-6]. Polyurethane (PU) is a sound-absorbing material with excellent performance, which is composed of solid polyurethane skeleton and holes [7-9]. Meanwhile, there are many tiny holes in the internal structure of porous sound-absorbing materials. Thus, sound waves can be transmitted in the gaps and microholes, which will produce friction and some viscous resistance between the material and the hole wall for consuming sound energy.

The sound absorption performance of a single soundabsorbing material is limited. The soft PU foam has better sound absorption performance for medium- and high-frequency noise. However, the low-frequency sound absorption performance is not high. In order to improve the low-frequency sound absorption performance, nanoparticles can be added to improve its performance. Sung et al. [6] used magnesium hydroxide fillers to prepare polyurethane syntactic foam to improve its acoustic properties, which not only increased the damping motion of the fillers but also increased the number of partial openings, thereby improving the sound absorption efficiency. When the open porosity was 0.63 , the noise reduction coefficient was about $70 \%$ higher than that of no fillers. Khanouki and Ohadi [7] used polyurethane foam as the base material and added silica $\left(\mathrm{SiO}_{2}\right)$ nanoparticles to improve its acoustic damping. In the frequency range of $500-1000 \mathrm{~Hz}$, the sound absorption properties of PU foam samples containing only $0.05 \mathrm{wt} \%$ nanoparticles increased 
greatly (over 90\%), but the sound-absorbing performance in the low-frequency range was not much improved. Baek and Kim [10] manufactured PU composite foam containing silicone-acrylic filler particles to test the sound absorption performance. When the content of nanoparticles was $2 \mathrm{wt} \%$, the maximum value of sound absorption coefficient was increased by 0.12 compared with the $\mathrm{PU}$ foam without addition. When the frequency was $1000 \mathrm{~Hz}$, the sound absorption had not much improved, and its sound absorption coefficient was about 0.2. In addition, other materials can also be used to fill the PU foam. Chen and Jiang [11] proposed a new type of acoustic material, by adding different content $(2 \%, 4 \%, 6 \%$, and $8 \%)$ of bamboo slices or bamboo stems to prepare PU foam composite materials to improve the acoustic performance of PU foam. Experiment results showed that the composite foam significantly improved its sound absorption performance, especially in the low-frequency region $(100 \mathrm{~Hz}-630 \mathrm{~Hz})$.

In recent years, different theoretical models had been reported to predict the sound absorption performance of porous absorbent materials. One of the most commonly used models was the fiber absorbing material model based on a large number of impedance tube measurements and curve fitting proposed by Delany and Bazley [12]. This model provided a good estimate of the characteristic impedance and propagation constant at frequencies above $250 \mathrm{~Hz}$. However, there was a significant error in prediction at lower frequencies. Further updates and improvements were suggested by Miki $[13,14]$. Gibson and Ashby [15] introduced dynamic permeability and dynamic tortuosity factor to study the lowfrequency and high-frequency sound propagation characteristics of the pore structure in 1987. Meanwhile, the viscous characteristic length of pore was defined to predict the highfrequency asymptotic behavior of the dynamic shape of pore structure. Allard and Champoux [16-18] derived the expressions of effective density and effective bulk elastic modulus of porous sound-absorbing materials in 1991 and introduced the thermal characteristic length of pores to study the problem of heat dissipation at the boundary layer of porous saturated media. Then, in 1992, the JohnsonChampoux-Allard semiempirical equivalent fluid model (JCA equivalent model) was established to characterize the propagation of sound waves in rigid porous materials. The experimental test results verified that the empirical model can be used to accurately estimate the characteristic impedance and material propagation coefficient.

In this paper, the PU foam filling with alumina $\left(\mathrm{Al}_{2} \mathrm{O}_{3}\right)$ nanoparticles was prepared. The morphology and sound absorption coefficient of the foam materials before and after filling were analyzed. In addition, the model of micro single hole was established in ANSYS Workbench. Most of the simulation research was to study the macro-sound absorption performance through the impedance tube, but there was little research on the micro single hole. Thus, a microscopic single-hole model was established in the paper. The single-hole model can observe the internal sound absorption and energy dissipation process, and the loss factor was also studied.

\section{Experiment}

2.1. Raw Material. In the paper, a soft polyurethane foam (PU foam) purchased from Ganzhou Yongjia sponge products company was a low-density foam with a thickness of $20 \mathrm{~mm}$ and a diameter of $100 \mathrm{~mm}$. Ethanol was purchased from the Sinopharm Group Co., Ltd. The nano $\mathrm{Al}_{2} \mathrm{O}_{3}$ suspension (with a particle size of 300 nanometers) was purchased from Shanghai Physical and Chemical Analysis Equipment Company.

2.2. Preparation of Foam. Typically, the $\mathrm{PU}$ foam was cleaned for $15 \mathrm{~min}$ under the solvent of alcohol and water volume ratio of $1: 3$ and then put it in oven to dry at $80^{\circ} \mathrm{C}$. The dried PU foam was placed in a Petri dish and soaked in a $\mathrm{Al}_{2} \mathrm{O}_{3}$ suspension. The foam was completely immersed in suspension and was soaked for about $1 \mathrm{~h}$. Then, the foam was dried at $80^{\circ} \mathrm{C}$ until it was completely dry. The density and porosity of PU foam were $14.08 \mathrm{~kg} \cdot \mathrm{m}^{-3}$ and 0.892 , respectively. The density and porosity of $\mathrm{Al}_{2} \mathrm{O}_{3}$ - $\mathrm{PU}$ foam were $31.21 \mathrm{~kg} \cdot \mathrm{m}^{-3}$ and 0.704 , respectively.

2.3. Test Instruments. X-ray diffraction (XRD) patterns were recorded with a Rigaku D/max $2250 \mathrm{~V}$ diffractometer operating with $\mathrm{Cu} \mathrm{K} \alpha$ radiation. The operation voltage and current were set as $40 \mathrm{kV}$ and $100 \mathrm{~mA}$, respectively. Scanning electron microscope (FESEM) images were acquired using S-4800 operated at an acceleration voltage of $5 \mathrm{kV}$. Sound absorption coefficient was explored by 4206 impedance tube. All samples had a thickness of $20 \mathrm{~mm}$ and a diameter of $100 \mathrm{~mm}$, and the tested frequency range was $0-1250 \mathrm{~Hz}$. The American MacPritice AutoPore Iv 9510 mercury porosimeter was used to detect and analyze the porosity of foam materials.

\section{Results and Discussion}

3.1. XRD Pattern and SEM Analysis of Foam. Figure 1 shows the XRD images of $\mathrm{PU}$ foam and $\mathrm{Al}_{2} \mathrm{O}_{3} / \mathrm{PU}$ composite foam. According to the experimental results, the $\mathrm{PU}$ foam had a wide steamed bread peak at $20^{\circ}$. All the diffraction peaks of $\mathrm{Al}_{2} \mathrm{O}_{3} / \mathrm{PU}$ composite foam can be indexed as amorphous $\mathrm{PU}$ and $\mathrm{Al}_{2} \mathrm{O}_{3}$ with the space group R-3c (167) (JPCD NO.100173). The lattice constants of $\mathrm{Al}_{2} \mathrm{O}_{3}$ were $a=b=4.758$, $c=12.991 \AA, \alpha=\beta=90^{\circ}$, and $\gamma=120^{\circ}$. No other impurity peaks were observed, which indicated that the samples were only composed of $\mathrm{PU}$ and $\mathrm{Al}_{2} \mathrm{O}_{3}$. Figure 2 shows the SEM images of $\mathrm{PU}$ foam and $\mathrm{Al}_{2} \mathrm{O}_{3} / \mathrm{PU}$ composite foam at different magnifications. The selected magnifications were 20 times and 5000 times. The existence of $\mathrm{Al}_{2} \mathrm{O}_{3}$ can be seen from the change of diffraction peak intensity. When the magnification was 20 times, it can be seen that the foam was composed of many small single pores similar to a tetradecahedron model (6 squares and 8 regular hexagons). When the magnification was 5000 times, it can be clearly observed that the $\mathrm{Al}_{2} \mathrm{O}_{3}$ nanoparticles were well attached to the foam skeleton and the distribution was relatively uniform. 


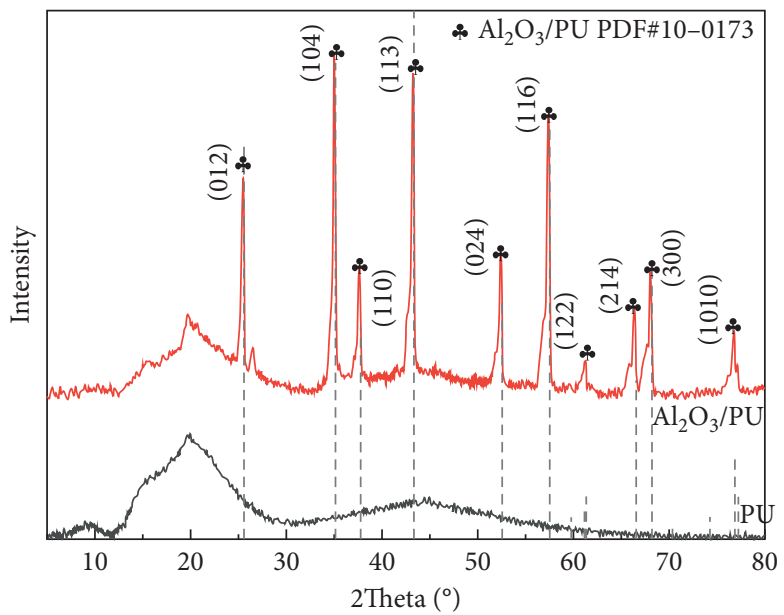

Figure 1: XRD pattern of PU foam and $\mathrm{Al}_{2} \mathrm{O}_{3} / \mathrm{PU}$ composite foam.

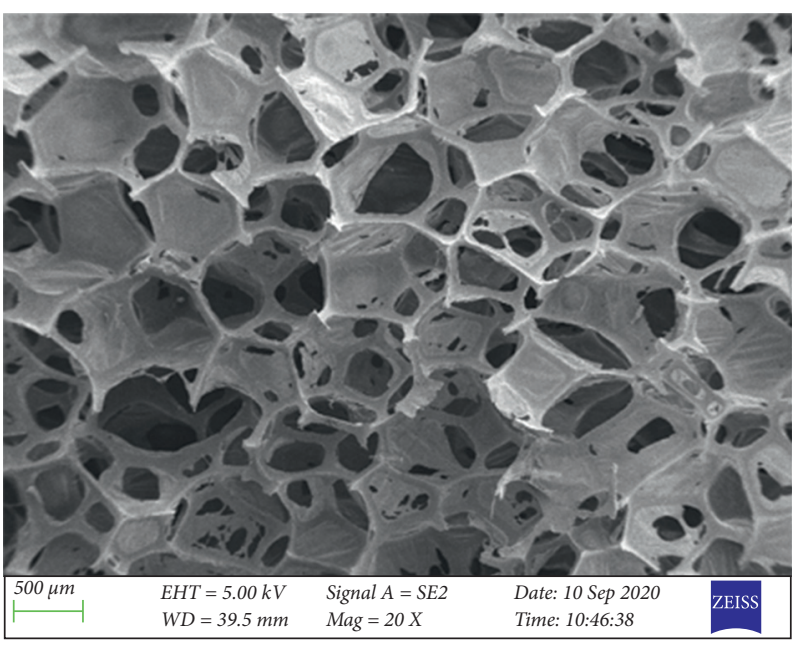

(a)

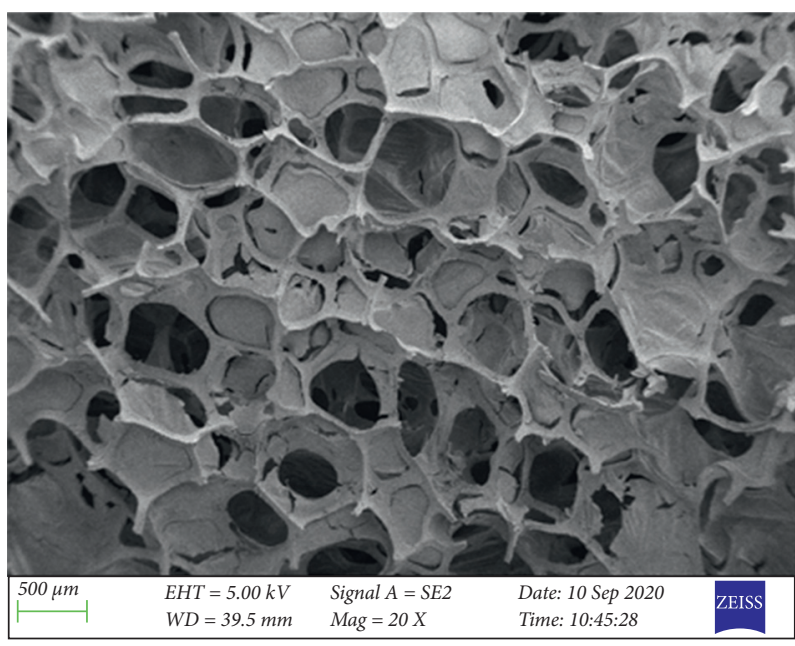

(c)

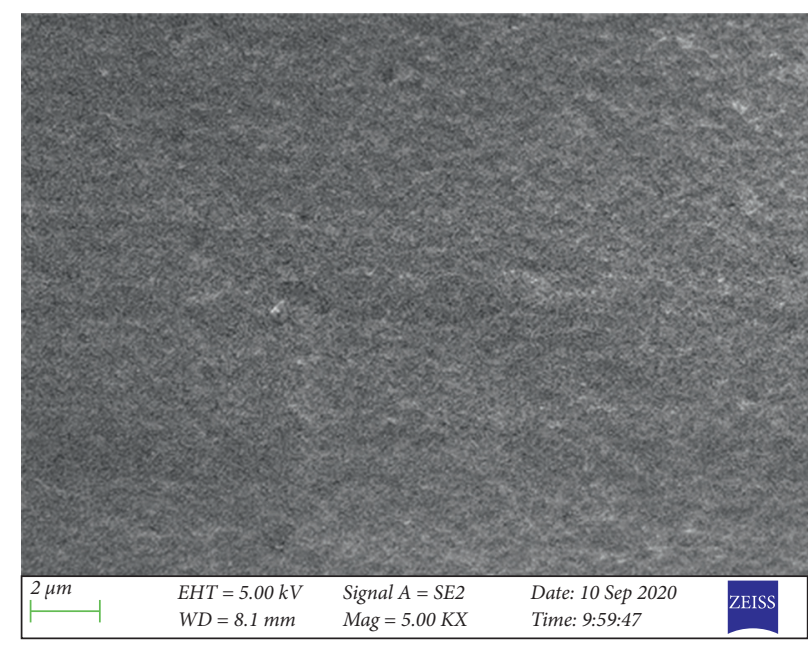

(b)

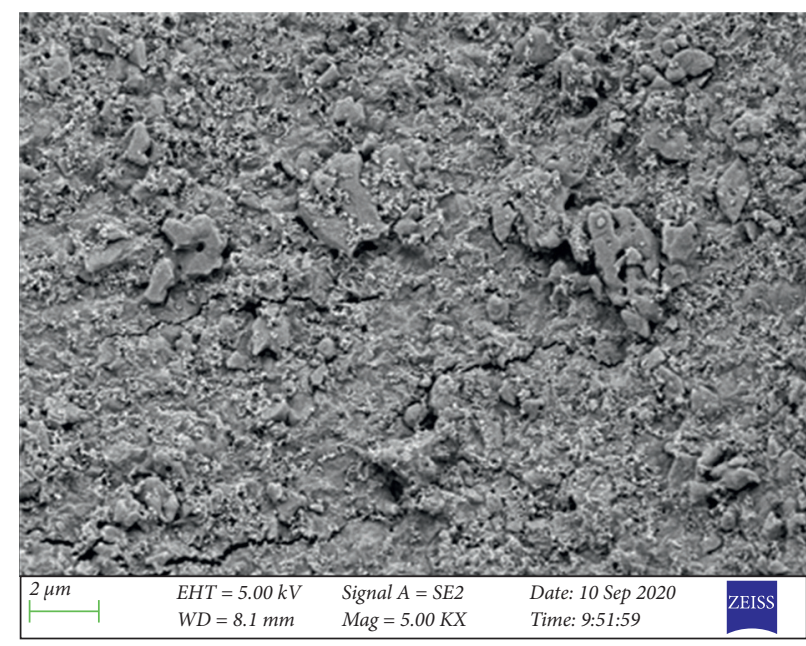

(d)

Figure 2: SEM images of (a, b) PU foam and (c, d) $\mathrm{Al}_{2} \mathrm{O}_{3} / \mathrm{PU}$ composite foam. 
3.2. Sound Absorption Coefficient. The sound coefficient of different PU foam samples was varied with frequency as shown in Figure 3. It can be seen that the sound absorption coefficient of $\mathrm{PU}$ foam and $\mathrm{Al}_{2} \mathrm{O}_{3}$-PU foam materials generally increased with the increase of frequency in the lowfrequency range $(50 \mathrm{~Hz}-1250 \mathrm{~Hz})$. The sound absorption performance was unstable between $50 \mathrm{~Hz}$ and $250 \mathrm{~Hz}$, and sound coefficient $\alpha$ had a tendency to vibrate up and down. The PU filled with $\mathrm{Al}_{2} \mathrm{O}_{3}$ nanoparticle composite material had better sound absorption performance than the pure $\mathrm{PU}$ foam. The $\alpha$ difference value between $\mathrm{PU}$ and $\mathrm{PU} / \mathrm{Al}_{2} \mathrm{O}_{3}$ increased with the increase of frequency, which reached the maximum difference value of 0.11 and increased about $70 \%$ at $1250 \mathrm{~Hz}$. It can be seen that filling $\mathrm{PU}$ foam with $\mathrm{Al}_{2} \mathrm{O}_{3}$ nanoparticles could effectively improve the sound absorption performance in the low-frequency range.

3.3. Simulation Calculation of Single Hole. The macroscopic sound absorption performance of porous materials was determined by the microstructure, and its microstructure must be analyzed. Based on PU foam SEM images, a singlehole geometric model was established. The established model was essentially a Kelvin model, which was the predecessor of the Voronoi model. The air temperature was set at $20^{\circ} \mathrm{C}$, and the density and porosity were entered according to the test values. According to the empirical formulas of the JCA equivalent model, the sound absorption process of single hole was simulated.

Figure 4(a) shows the SEM image of the PU foam. From the image, the microstructure distribution of the foam can be seen more clearly, which can be indexed as tetradecahedron (6 squares and 8 regular hexagons). The regular tetradecahedron model was constructed (Figure 4(b)), and then the shell was removed to extract the skeleton structure, as shown in Figure 4(c). Then, the model was analyzed in ANSYS Workbench to form the single-hole acoustic cavity model, as shown in Figure 4(d). Figure 4(e) shows the model after meshing. It should be divided evenly and finely, and the part where the acoustic cavity model contacted with the singlehole skeleton required a predefined boundary layer grid. The finite element acoustic cavity model was established to simulate the sound absorption and the loss factor of sound waves in the foam structure.

When the sound wave passed through the porous foam material, the sound pressure on each surface of the singlehole acoustic cavity was approximately the same. Therefore, the sound pressure of $1 \mathrm{~Pa}$ was applied to each surface of the single-hole regular tetradecahedron acoustic cavity, and there was a plane wave outside. We set the thermal viscosity boundary on the surface of the skeleton. Figures 5(a) and 5 (b) show the acoustic cavity ( $\mathrm{PU}$ and $\mathrm{Al}_{2} \mathrm{O}_{3} / \mathrm{PU}$ ) with the skeleton removed. The model was cut in the middle, so that the image change of the single-hole sound absorption can be better observed from the sound pressure diagram. It can also be clearly seen that the sound pressure changed with frequency, and the selected frequencies were $125 \mathrm{~Hz}, 375 \mathrm{~Hz}$, $625 \mathrm{~Hz}, 875 \mathrm{~Hz}, 1125 \mathrm{~Hz}$, and $1250 \mathrm{~Hz}$. From the average sound pressure change curve in the low-frequency range

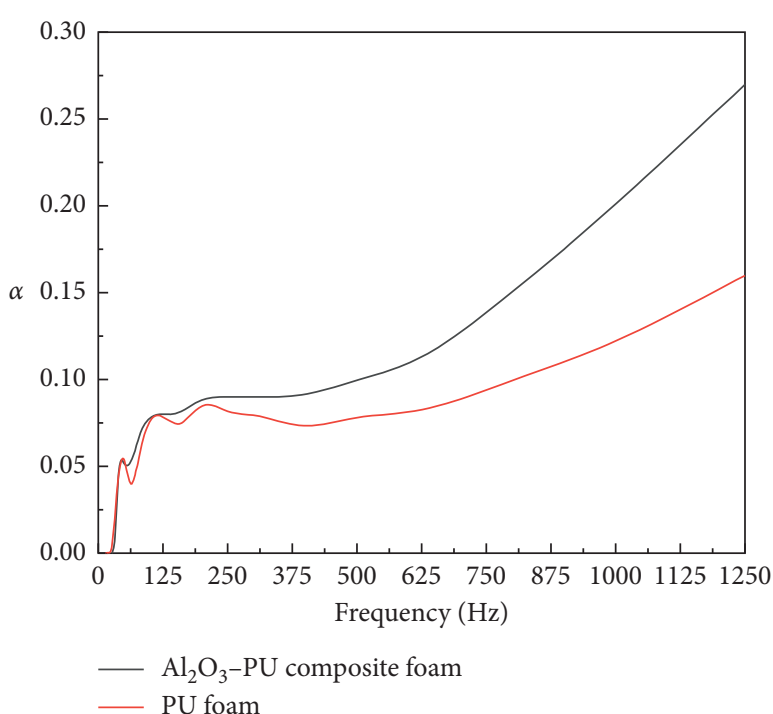

FIgURE 3: Sound absorption coefficient ( $\alpha$ ) diagram of PU foam and $\mathrm{Al}_{2} \mathrm{O}_{3}$-PU foam.

(Figure 5(c)), it can be seen that the average single-hole sound pressure for PU foam showed a trend of rising first and then falling in $50-1250 \mathrm{~Hz}$. The highest point was about $812.5 \mathrm{~Hz}$, but it had not yet reached the lowest point. The single-hole average sound pressure showed a trend of rising first, then falling, and rising again for $\mathrm{Al}_{2} \mathrm{O}_{3} / \mathrm{PU}$ foam. In addition, the highest point was around $593.75 \mathrm{~Hz}$, and the lowest point was around $937.5 \mathrm{~Hz}$. In terms of sound pressure, the sound absorption process of a single hole was a process of absorption and dissipation. Meanwhile, the absorption and dissipation process of $\mathrm{Al}_{2} \mathrm{O}_{3} / \mathrm{PU}$ foam was faster than that of PU foam. It can be inferred that this cycle was repeated at a later frequency.

The total energy dissipation of $\mathrm{PU}$ and $\mathrm{Al}_{2} \mathrm{O}_{3} / \mathrm{PU}$ foam could be divided into acoustic potential energy dissipation and acoustic kinetic energy dissipation, as shown in Figures 6 and 7. From the cloud diagram of the acoustic cavity model (Figure 6), the acoustic potential energy dissipation was mainly concentrated in the central area, and the kinetic energy was dispersed between the central and the outer edge to form a ring, in which the red area was the maximum value. In Figure 7(a), the left axis represented acoustic energy storage, and the right axis represented acoustic energy dissipation. It can be seen that the acoustic energy storage of $\mathrm{PU} / \mathrm{Al}_{2} \mathrm{O}_{3}$ composite was lower than that of $\mathrm{PU}$ foam, while the acoustic energy dissipation of $\mathrm{PU} / \mathrm{Al}_{2} \mathrm{O}_{3}$ composite was higher than that of PU foam. Figure 7(b) shows the loss factor for single-hole sound absorption. The sound loss factor was the ratio of system energy dissipation and energy storage. Both energy dissipation and energy storage would fluctuate continuously with changes in frequency. The loss factor of single-hole sound absorption could be obtained by calculation, which had an important influence on the vibration response of the predictive structure. It tended to change with frequency or temperature, showing a trend similar to the sound absorption coefficient. Zhang et al. [19] designed and successfully 


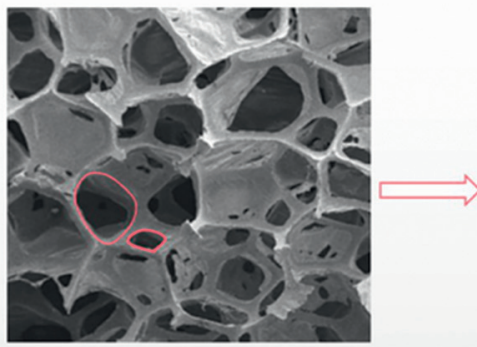

(a)

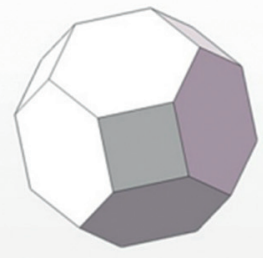

(b)

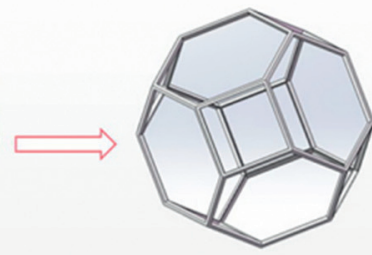

(c)

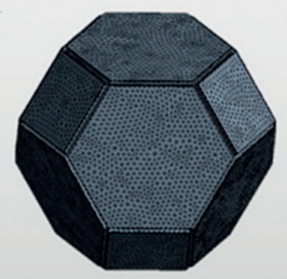

(e)

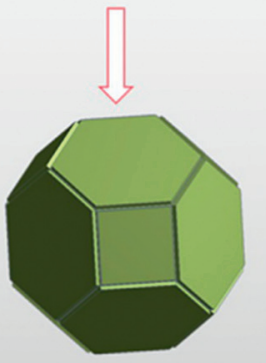

(d)

FIGURE 4: The process of establishing a single-hole acoustic cavity model.

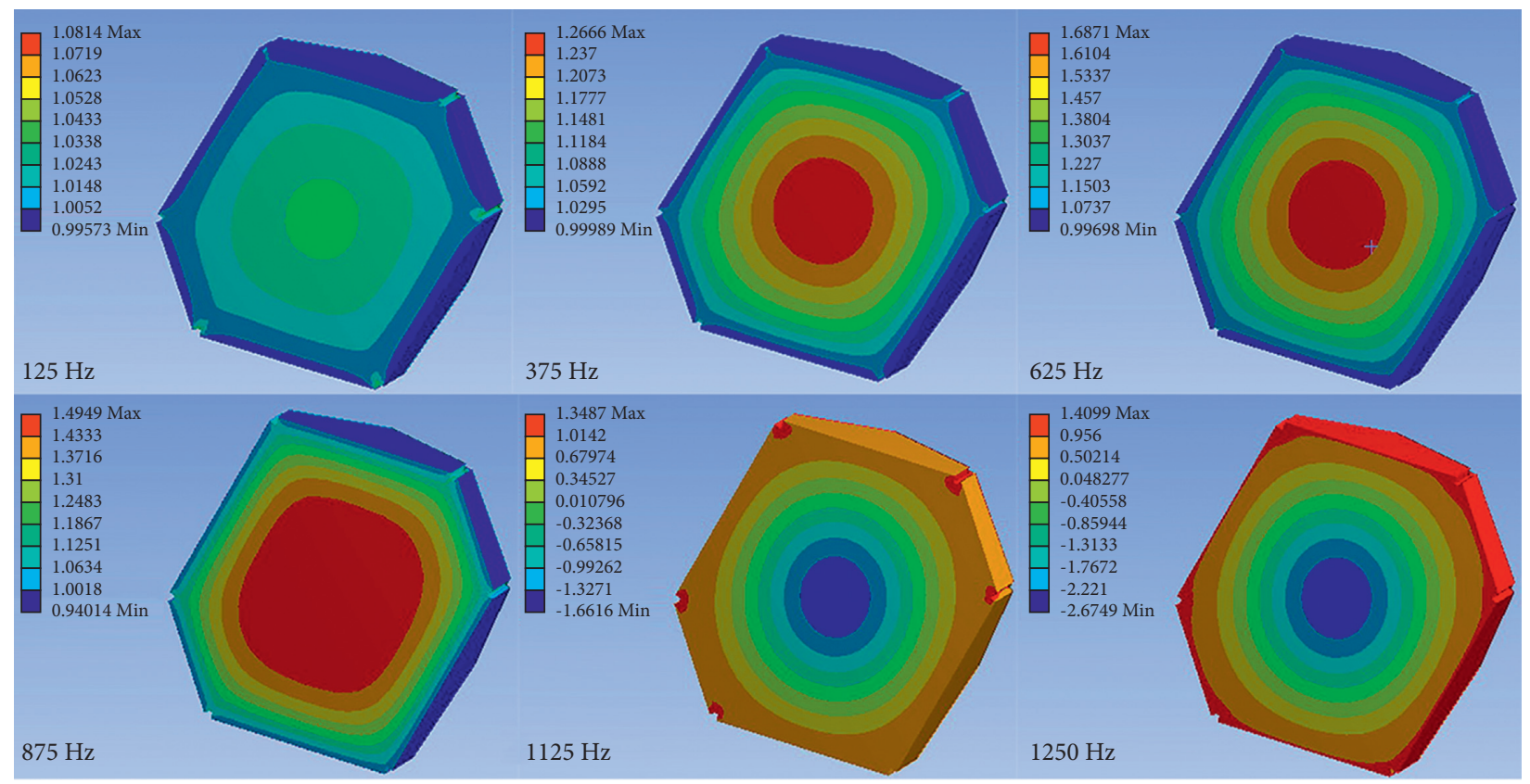

(a)

Figure 5: Continued. 


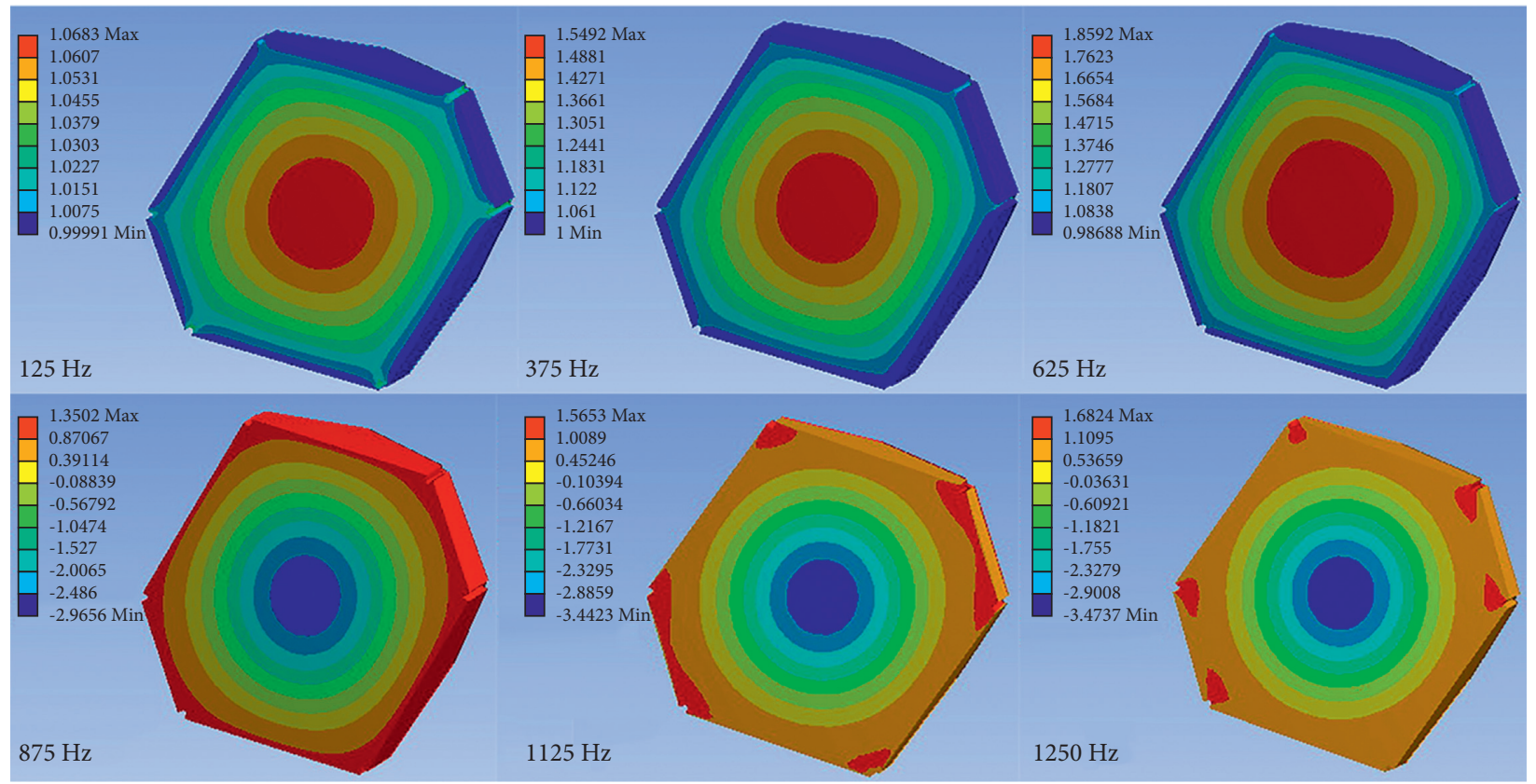

(b)

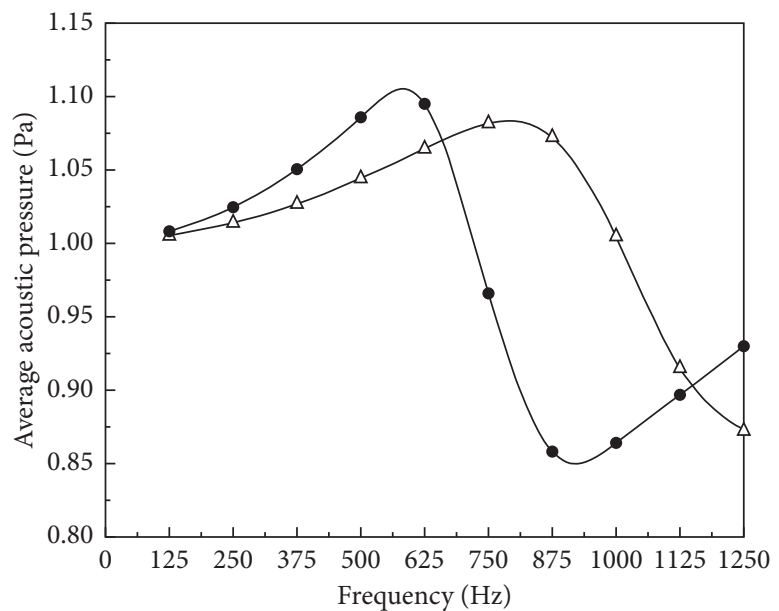

- $\mathrm{Al}_{2} \mathrm{O}_{3}-\mathrm{PU}$ composit foam

$\triangle \mathrm{PU}$ foam

(c)

Figure 5: (a) PU foam and (b) $\mathrm{Al}_{2} \mathrm{O}_{3} / \mathrm{PU}$ foam acoustic cavity section sound pressure topography in $125 \mathrm{~Hz}, 375 \mathrm{~Hz}, 625 \mathrm{~Hz}, 875 \mathrm{~Hz}$, $1125 \mathrm{~Hz}$, and $1250 \mathrm{~Hz}$. (c) The average sound pressure change curve of $\mathrm{PU}$ foam and $\mathrm{Al}_{2} \mathrm{O}_{3} / \mathrm{PU}$ foam.

prepared a high-damping polyurethane/hollow glass microsphere sound insulation material and measured the loss factor of the polyurethane composite material. In the range of -80 to $60^{\circ} \mathrm{C}$, the loss factor first increased and then decreased. The highest point was at $-20^{\circ} \mathrm{C}$, and the sound absorption performance was the best. Moradi et al. [20] measured the loss factor by studying the different ratios of PU and PMMA polymers. Thus, the loss factor of singlehole sound absorption can reflect the sound absorption coefficient of porous materials. From Figure 7, it can be seen that the loss factor of single hole first rose to the highest point and then decreased with the increase of frequency. The loss factor of $\mathrm{Al}_{2} \mathrm{O}_{3}$-PU reached the highest point earlier than that of $\mathrm{PU}$ in the frequency range of $0-6000 \mathrm{~Hz}$, and the highest points were $2750 \mathrm{~Hz}$ and $3500 \mathrm{~Hz}$, respectively. Meanwhile, the loss factor of $\mathrm{Al}_{2} \mathrm{O}_{3}$ PU was higher than that of PU from $500 \mathrm{~Hz}$ to $4500 \mathrm{~Hz}$. It can be predicted that the change rule of the sound absorption coefficient for $\mathrm{PU}$ foam and $\mathrm{Al}_{2} \mathrm{O}_{3}$-PU was similar to that of the loss factor. 


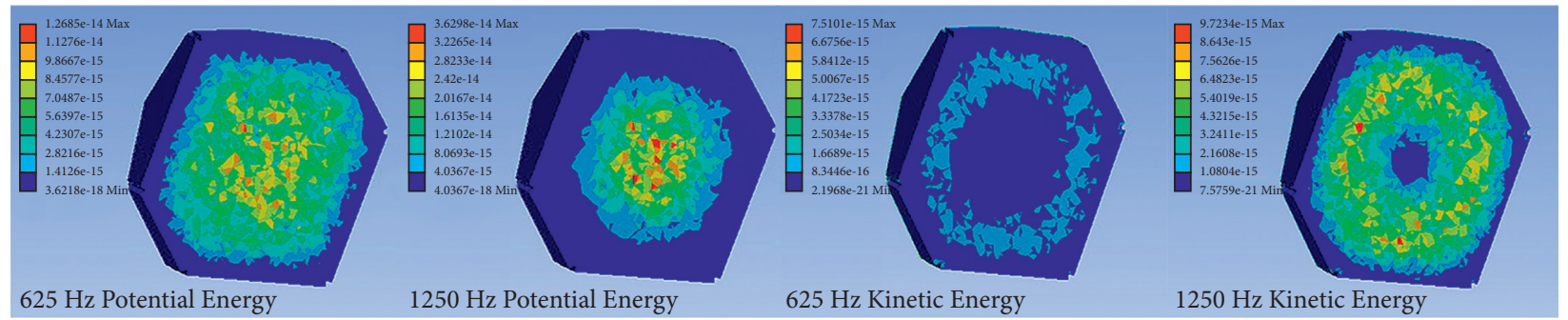

(a)

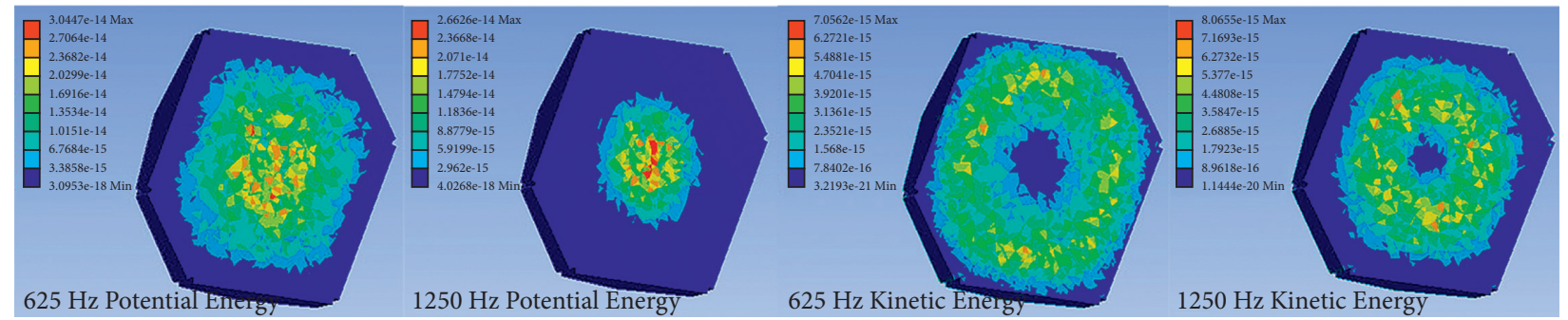

(b)

Figure 6: Acoustic potential energy and acoustic energy dissipation diagram at $625 \mathrm{~Hz}$ and $1250 \mathrm{~Hz}$ for (a) $\mathrm{PU}$ foam and (b) $\mathrm{PU} / \mathrm{Al}_{2} \mathrm{O}_{3}$ foam.

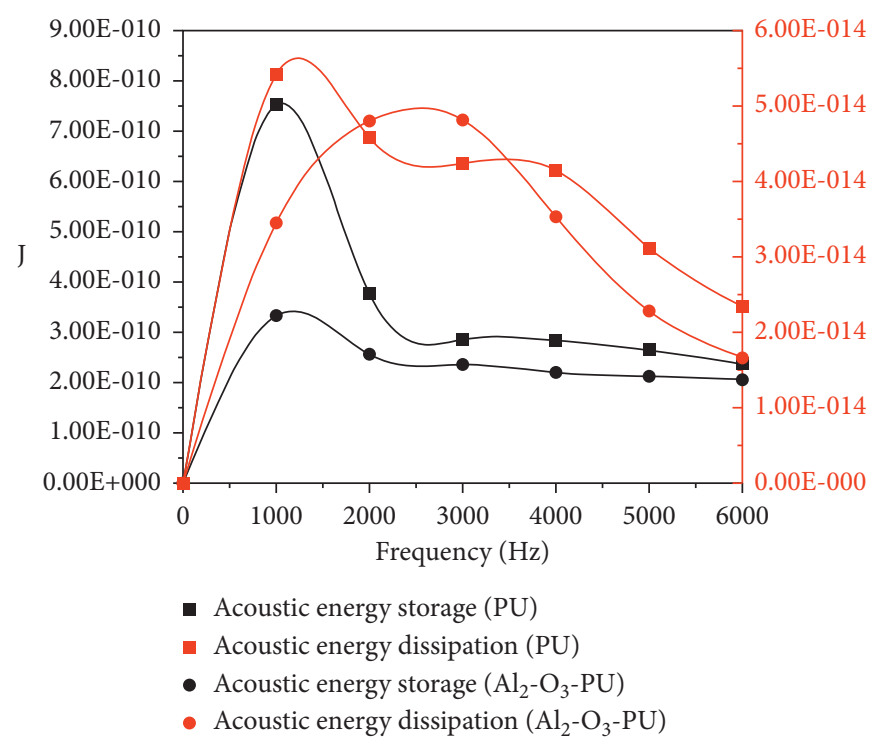

(a)

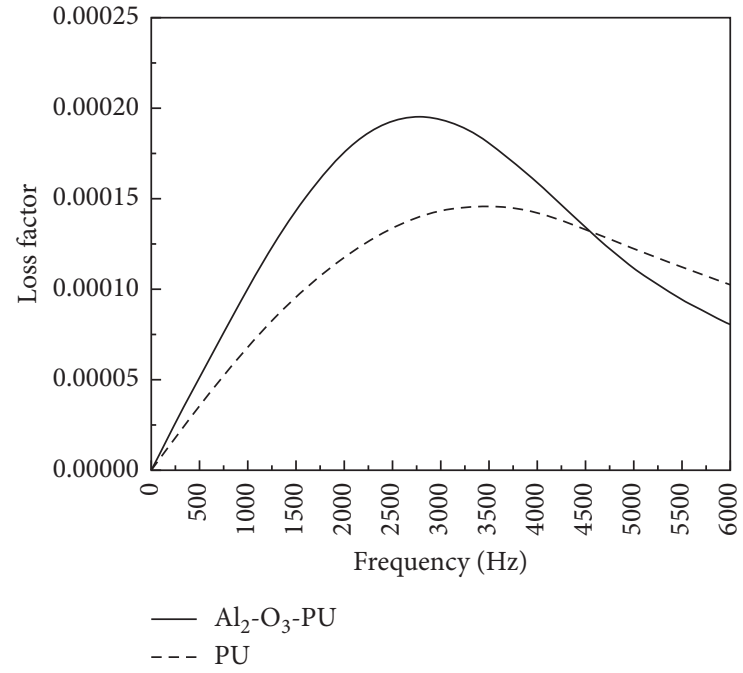

(b)

Figure 7: (a) Sound energy storage and sound energy dissipation of single-hole PU and $\mathrm{Al}_{2} \mathrm{O}_{3}-\mathrm{PU}$ foam. (b) Loss factor for single-hole sound absorption.

\section{Conclusion}

In this paper, a practical approach for obtaining $\mathrm{PU}$ composite foam directly soaked with nano $\mathrm{Al}_{2} \mathrm{O}_{3}$ was proposed. The method was easy to operate for preparing composite foams. Compared with pure PU foam, the density and air flow resistivity of the $\mathrm{Al}_{2} \mathrm{O}_{3}$-PU composite samples were higher, but the porosity decreased. The sound absorption coefficients of different $\mathrm{PU}$ and $\mathrm{Al}_{2} \mathrm{O}_{3}$-PU foam samples generally increased with the increase of frequency in the lowfrequency range $(50 \mathrm{~Hz}-1250 \mathrm{~Hz})$. It can be seen that filling $\mathrm{PU}$ foam with $\mathrm{Al}_{2} \mathrm{O}_{3}$ nanoparticles could effectively improve the sound absorption performance in the low-frequency range. In addition, the microscopic single-hole model was established based on SEM images, and the absorption and dissipation process of $\mathrm{PU} / \mathrm{Al}_{2} \mathrm{O}_{3}$ foam was faster than that of PU foam. Through studying the sound energy storage and sound energy dissipation process, the loss factor can be calculated. The results showed that the loss factor of $\mathrm{Al}_{2} \mathrm{O}_{3}$ PU was higher than that of PU from $500 \mathrm{~Hz}$ to $4500 \mathrm{~Hz}$, and the highest points of $\mathrm{Al}_{2} \mathrm{O}_{3}$-PU and $\mathrm{PU}$ foam were $2750 \mathrm{~Hz}$ and $3500 \mathrm{~Hz}$, respectively. It meant that the sound absorption properties of $\mathrm{Al}_{2} \mathrm{O}_{3}$-PU foam were better, which was consistent with the experimental results. 


\section{Data Availability}

The data used to support the findings of this study are available from the corresponding author upon request.

\section{Conflicts of Interest}

The authors declare that they have no conflicts of interest.

\section{Acknowledgments}

This study was supported by the financial support from Open Fund of State Key Laboratory of Power Grid Environmental Protection (GYW51202001548).

\section{References}

[1] C. Arenas, C. Leiva, L. F. Vilches, and H. Cifuentes, "Use of co-combustion bottom ash to design an acoustic absorbing material for highway noise barriers," Waste Management, vol. 33, no. 11, pp. 2316-2321, 2013.

[2] K. Kalauni and S. J. Pawar, "A review on the taxonomy, factors associated with sound absorption and theoretical modeling of porous sound absorbing materials," Journal of Porous Materials, vol. 26, no. 6, pp. 1795-1819, 2019.

[3] A.-E. Tiuc, H. Vermeşan, T. Gabor, and O. Vasile, "Improved sound absorption properties of polyurethane foam mixed with textile waste," Energy Procedia, vol. 85, pp. 559-565, 2016.

[4] V. G. Geethamma, G. Kalaprasad, G. Groeninckx, and S. Thomas, "Dynamic mechanical behavior of short coir fiber reinforced natural rubber composites," Composites Part A: Applied Science and Manufacturing, vol. 36, no. 11, pp. 1499-1506, 2005.

[5] F. Saint-Michel, L. Chazeau, and J.-Y. Cavaillé, "Mechanical properties of high density polyurethane foams: II Effect of the filler size," Composites Science and Technology, vol. 66, no. 15, pp. 2709-2718, 2006.

[6] G. Sung, J. W. Kim, and J. H. Kim, "Fabrication of polyurethane composite foams with magnesium hydroxide filler for improved sound absorption," Journal of Industrial and Engineering Chemistry, vol. 44, pp. 99-104, 2016.

[7] M. A. Khanouki and A. Ohadi, "Improved acoustic damping in polyurethane foams by the inclusion of silicon dioxide nanoparticles," Advances in Polymer Technology, vol. 37, no. 8, pp. 2799-2810, 2018.

[8] S. Basirjafari, "Effects of CNT loading on cellular structures and sound absorption of PU foams," Micro \& Nano Letters, vol. 13, no. 10, pp. 1501-1505, 2018.

[9] J. Allard and N. Atalla, Propagation of Sound in Porous media: Modelling of Sound Absorbing Materials, John Wiley \& Sons, New York, NY, USA, 2nd edition, 2009.

[10] S. H. Baek and J. H. Kim, "Polyurethane composite foams including silicone-acrylic particles for enhanced sound absorption via increased damping and frictions of sound waves," Composites Science and Technology, vol. 198, Article ID 108325, 2020.

[11] S. Chen and Y. Jiang, "The acoustic property study of polyurethane foam with addition of bamboo leaves particles," Polymer Composites, vol. 39, no. 4, pp. 1370-1381, 2018.

[12] M. E. Delany and E. N. Bazley, "Acoustical properties of fibrous absorbent materials," Applied Acoustics, vol. 3, no. 2, pp. 105-116, 1970.
[13] Y. Miki, "Acoustical properties of porous materials. m," Journal of the Acoustical Society of Japan, vol. 11, no. 1, pp. 19-24, 1990.

[14] Y. Miki, "Acoustical properties of porous materials. g," Journal of the Acoustical Society of Japan, vol. 11, no. 1, pp. 25-28, 1990.

[15] L. J. Gibson and M. F. Ashby, Cellular Solids: Structure \& Properties, Cambridge University, Cambridge, England, 2nd edition, 1997.

[16] J. Allard, Propagation of Sound in Porous media: Modelling Sound Absorbing Materials, Elsevier, Amsterdam, Netherlands, 1st edition, 1993.

[17] Y. Champoux and M. R. Stinson, "On acoustical models for sound propagation in rigid frame porous materials and the influence of shape factors," Journal of the Acoustical Society of America, vol. 92, no. 2, pp. 1120-1131, 1992.

[18] N. Atalla, R. Panneton, F. C. Sgard, and X. Olny, "Acoustic absorption of macro-perforated porous materials," Journal of Sound and Vibration, vol. 243, no. 4, pp. 659-678, 2001.

[19] Z. Zhang, H. Jiang, R. Li et al., "High-damping polyurethane/ hollow glass microspheres sound insulation materials: p," Journal of Applied Polymer Science, vol. 138, no. 10, Article ID 49970, 2021.

[20] G. Moradi, P. Nassiri, A. Ershad-Langroudi, and M. R. Monazzam, "Acoustical, damping and thermal properties of polyurethane/poly(methyl methacrylate)-based semiinterpenetrating polymer network foams," Plastics, Rubber and Composites, vol. 47, no. 5, pp. 221-231, 2018. 